\title{
Gaëtan Brulotte, Doppia esposizione
}

\section{Carminella Biondi}

\section{Q OpenEdition}

\section{Journals}

\section{Edizione digitale}

URL: http://journals.openedition.org/studifrancesi/7068

DOI: $10.4000 /$ studifrancesi.7068

ISSN: 2421-5856

\section{Editore}

Rosenberg \& Sellier

\section{Edizione cartacea}

Data di pubblicazione: 1 septembre 2010

Paginazione: 419-420

ISSN: 0039-2944

\section{Notizia bibliografica digitale}

Carminella Biondi, «Gaëtan Brulotte, Doppia esposizione», Studi Francesi [Online], 161 (LIV | II) | 2010, online dal 30 novembre 2015, consultato il 11 janvier 2021. URL: http://journals.openedition.org/ studifrancesi/7068 ; DOI: https://doi.org/10.4000/studifrancesi.7068

Questo documento è stato generato automaticamente il 11 janvier 2021.

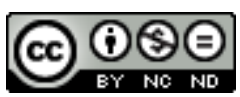

Studi Francesi è distribuita con Licenza Creative Commons Attribuzione - Non commerciale - Non opere derivate 4.0 Internazionale. 


\title{
Gaëtan Brulotte, Doppia esposizione
}

\author{
Carminella Biondi
}

\section{NOTIZIA}

GAËTAN BRULOTTE, Doppia esposizione, tr. it. di Rahel Francesca GENRE, Ripa di Fagnano Alto (AQ), Il Sirente, 2008, pp. 135.

1 Pubblicato in lingua originale nel 1979, con il titolo L'emprise, è subito diventato un best-seller, più volte ristampato e selezionato fra i cento migliori romanzi quebecchesi. Parte come una storia apparentemente banale, che si fa però sempre più inquietante $a$ mano a mano che si procede nella lettura. Uno scrittore di buona reputazione, che ha sempre guardato il mondo attraverso il filtro rassicurante della sua macchina fotografica, per poi tradurlo senza rischi sulla pagina scritta, comodamente seduto nel suo studio protettivo come una campana di vetro, decide un giorno di scegliere come protagonista del suo nuovo romanzo un personaggio squinternato, che veste in maniera strana, si muove in maniera ancora più strana, sembra sempre indaffarato, ma in realtà non fa nulla, se non spostarsi in continuazione senza meta, con una misteriosa cartella che non abbandona mai. Lo scrittore ne è sempre più affascinato (un fascino fatto in eguale misura di attrazione e repulsione) e si lascia coinvolgere completamente nella vita di questo personaggio che si rivela sempre più problematico ed inquietante: lo scrittore scoprirà che è esibizionista, "vizio" (vissuto però dal protagonista come un'epifania) a causa del quale sarà più volte arrestato, rinchiuso in un manicomio $\mathrm{e}$ torturato. Il processo di identificazione, che si realizza a poco a poco tra lo scrittore e il suo personaggio raggiunge forme di parossismo, costringendo il primo ad implicarsi sempre più a fondo in un mondo melmoso, misero, patetico, fino a valicare i limiti della legalità e a tentare di distruggere "il folle", scelto come soggetto della sua storia - che osa resistergli - per meglio impossessarsene, perché per lo scrittore Charles Block/ Gaëtan Brulotte, la forma estrema di possesso è la distruzione.

2 Un bel romanzo che, nella sua apparente bizzarria, pone sul tappeto problemi importanti, sotto il profilo sociale e letterario, come quello della marginalità, anche 
sessuale, percepita con disprezzo dalla comunità, ma vissuta quasi come sublimazione e poesia da coloro che vi sono implicati, o quello della brutalità del trattamento manicomiale per ricondurre l'anomalia alla norma; il problema dell'implicazione dello scrittore nel vissuto che narra, e degli eventuali limiti oltre i quali non è possibile spingersi senza il rischio di perdersi o di auto-distruggersi. E infine, il problema quanto mai attuale del rapporto fra lo scrittore e il suo personaggio e sui diritti di proprietà della storia che implica una lotta all'ultimo sangue, soprattutto da parte del personaggio, in realtà soccombente, che tenta di realizzare un rovesciamento di ruoli per liberarsi, appunto, da quell'emprise che dà il titolo al romanzo nella versione originale. 